COMMENT

https://doi.org/10.1057/s41599-019-0235-8

\title{
Overcoming disciplinary divides in higher education: the case of agricultural economics
}

Desmond $\mathrm{Ng}^{1} \&$ Kerry Litzenberg ${ }^{1}$

\begin{abstract}
As global problems have become ever more complex, the production and organization of knowledge in society is increasingly based on the sharing, integration and collaboration of diverse experiences. For instance, global 'grand challenges', such as world hunger, poverty, climate change, and sustainability often require an interdisciplinary (ID) approach, in which integrating the insights of different disciplines provides a more comprehensive solution than can be offered by any given discipline. Universities or higher educational institutions face increasing pressures to engage in such interdisciplinary collaboration. This interdisciplinarity, however, raises particular organizational challenges to departments in higher educational institutions. In particular, while departments have been traditionally organized around a disciplinary core, interdisciplinarity has placed increasing pressures on departments, such as agricultural economics, to integrate insights from disciplines that do not advance a department's disciplinary core. Few ID researchers have addressed the issue of how this internal conflict can be resolved in a departmental setting. Resolving this internal conflict is important to developing a greater interdisciplinarity among the disciplines of departmental units where a greater variety of disciplinary insights can be drawn upon to solve complex social problems. Here, we call for a unique organizational structure that can resolve this internal conflict. In using agricultural economics departments as a case study, we appeal to a concept of a "gatekeeper" whose role is to institute "loosely coupled" connections that can reconcile a department's internal conflicts. This "gatekeeper" can advance the "normal science" of a department's core and peripheral disciplines, while at the same time support a 'common ground' that appeals to these disciplines' common interests. A key conclusion is that "gatekeepers" can sustain the integration of disciplinary insights necessary for the advancement of interdisciplinarity in higher educational institutions.
\end{abstract}

\footnotetext{
${ }^{1}$ Department of Agricultural Economics, Texas A\&M University, College Station, TX, USA. Correspondence and requests for materials should be addressed to D.N. (email: dng@tamu.edu) or to K.L. (email: litz@tamu.edu)
} 


\section{Introduction}

The world has problems, while universities have departments. (Brewer, 1999, p. 328) Higher educational institutions are at a crossroads. Society has placed increasing pressures on universities to solve global "grand challenges" (Maxwell and Benneworth, 2018 , p. 2). Grand challenge problems often require an interdisciplinary (ID) approach (Repko and Szostak, 2017, p. 9) that integrates the insights of multiple disciplines. For instance, grand challenge problems surrounding world poverty, hunger, conflict, ecological sustainability and agricultural development exhibit complex challenges that require an integration of insights from disciplines involving economics, business, sociology, psychology, nutrition, ecology and other related disciplines. To respond to these grand challenges, various United States federal agencies, such as United States Department of Agriculture (U.S.D.A.), National Science Foundation (N.S.F.), and National Aeronautics and Space Administration (N.A.S.A.), have altered their funding requirements to place a greater prioritization on interdisciplinary research teams (Mooney et al., 2013). In particular, since the passing of the Agricultural Research, Extension and Education Reform Act of 1998, the U.S.D.A.'s National Institute of Food and Agriculture (N.I.F.A.) has prioritized its competitive funding programs to support interdisciplinary collaborations that address climate change, food safety, and sustainable bioenergy (N.I.F.A., 2018). This prioritization on interdisciplinarity is particularly important to an applied discipline such as agricultural economics. Agricultural economics is deeply rooted in the discipline of economics, yet due to its applied orientation, requires integrating various disciplines including: agricultural engineering, climate science, agricultural finance, animal husbandry, plant pathology, consumer behavior, and agricultural policy into a complex decision-making process. Due to its integrated nature, a recent assessment of the agricultural economics profession has renewed calls for greater interdisciplinarity (Mooney et al., 2013).

Yet, in spite of the merits of interdisciplinarity, many agricultural economics departments-especially those in land grant universities in the United States-are organized around a core mission to advance the use of economics in solving food, fiber, energy and related environmental sustainability problems. Philosophically speaking, these departments' core mission are organized around a 'normal science' (Kuhn, 1962) that involves developing a shared commitment to the theoretical assumptions, beliefs, values, and techniques of their parent economics discipline. The advantages of this shared commitment are that it develops a discipline's legitimacy (Kuhn, 1962) and offers a more focused attempt to examining empirical realities without needing to clarify conflicting theories and assumptions (Markoczy and Deeds, 2009). The challenge with this advancement of "normal science" is that it strongly resists or rejects the integration of insights from disciplines that do not share the same commitment (Becher and Trowler, 2001; Kuhn, 1962; Maxwell and Benneworth, 2018). This resistance is borne out in agricultural economics departments. For instance, over the last thirty years, the growth of the agribusiness discipline (itself an ID effort with business schools) has been a significant contributor to the viability of many agricultural economics departments. Yet, agribusiness is often viewed as a peripheral discipline because it introduces competing theoretical assumptions, beliefs, values, and techniques that challenge the advancement of the "normal science" of economics in agricultural economics departments (Harling, 1995; Ng and Siebert, 2009).

While interdisciplinarity is key to addressing the complex challenges of agricultural economics, the challenge facing agricultural economics departments is they face an internal conflict that inhibits the integration of different disciplinary insights. This internal conflict speaks to a broader problem faced by many other departments in higher education. Departments on the one hand seek to advance the "normal science" of their disciplinary core, yet at the same time, face institutional pressures to integrate disciplines that do not conform to the "normal science" of their department's core (see also Batie, 2008; Kuhn, 1962; Maxwell and Benneworth, 2018). For instance, agricultural economic departments face institutional pressures from constituents (i.e., student demands, private donors, industry support, employers and academics) to advance teaching and research programs in the peripheral discipline of agribusiness (e.g., Cornell's Food Industry Management Programs, Purdue's International Agribusiness Business Program, Kansas State Agribusiness Management program). These institutional demands are largely a response to a concern that the economic core of agriculture economics departments is not sufficient to addressing the complex social challenges faced by agribusiness firms (Harling, 1995; King et al., 2010; Ng and Siebert, 2009; Sonka and Hudson, 1989). This was noted in King et al. (2010) where they describe,

A.C. Hoffman, vice president of Kraft Foods Company... stressed that the agribusiness economist should be trained not only in economics but also for general business management and went on to note traditional agricultural economics programs were not adequate for this purpose. ( $\mathrm{p}$. 565)

By drawing on the principles and practices of general business management, the agribusiness discipline offered an alternative to the economics of business decision making and has been important to addressing the institutional demands faced by agricultural economics departments. The challenge facing agricultural economics departments is that it can no longer be organized along a core economic discipline, but needs to contend with a peripheral discipline-agribusiness-that does not support the department's core economic mission. Resolving this internal conflict is an important problem not only for departments that house multiple disciplines, but also to ID research (Bammer, 2017; Brandstädter and Sonntag, 2016; Clark and Wallace, 2015; Jacob, 2015; Maxwell and Benneworth, 2018; Mooney et al., 2013; Pedersen, 2016). This is because while disciplines form the foundation of ID approaches (Repko and Szostak, 2017), the advancement of "normal science" promotes a shared commitment that rejects the insights of peripheral disciplines (Becher and Trowler, 2001; Kuhn, 1962; Maxwell and Benneworth, 2018) and thus undermines the very integration sought by ID research. In the case of agricultural economics, this internal conflict motivates the following research problem: How can agricultural economics departments be organized in ways that would facilitate the integration of insights from peripheral as well as core disciplines?

To address this problem, we appeal to the insights of ambidexterity research (Boumgarden et al., 2012; O'Reilly and Tushman, 2013; Raisch and Birkinshaw, 2008; Tushman and O'Reilly, 1996). A central tenet of ambidexterity is that in order to meet the complex challenges of the market, organizations face competing pressures to simultaneously attend to conflicting knowledge structures (Boumgarden et al. 2012) or 'logics' (Carter, 2015; Prahalad and Bettis, 1986; Tushman and Murmann, 1998). A logic is analogous to Kuhn's (1962) concept of a discipline that consists of an organization's assumptions, commitments, experiences, values and beliefs (Prahalad and Bettis, 1986). Ambidexterity research argues that organizations face competing logics/ disciplines where "loosely coupled" connections offer a means to reconcile these inconsistent logics (Benner and Tushman, 2003; Boumgarden et al., 2012; Danneels, 2003; Raisch and Birkinshaw, 
2008). Loosely coupled exchanges are defined by a semiautonomous relationship, where peripheral elements of a complex system, are "linked but not determined" by the system's core (Danneels, 2003). Loose coupling reduces organizational conflict by separating an organization's core logic/discipline from other competing or peripheral logics/disciplines, while at the same time seeking a "common ground" between these logics/ disciplines (Carter, 2015; Danneels, 2003; Raisch and Birkenshaw, 2008). Business studies have shown that "gatekeepers" (Tushman and Katz, 1980; Tushman and Nadler, 1986) often involving senior project leaders (see also Boumgarden et al. 2012; Raisch and Birkenshaw, 2008; Tushman and O'Reilly, 1996) are central to instituting such loosely coupled exchanges. "Gatekeepers" institute loose coupling exchanges by promoting communications across an organization's business units (Tushman and Katz, 1980). In higher educational settings, we argue that senior or tenured faculty members play an important "gatekeeping" role in instituting a department's loosely coupled exchanges. With such loose coupling, 'gatekeepers' advocate the growth of a department's peripheral discipline in ways that are separate from a department's core. While at the same time, "gatekeepers" also advocate a "common ground" (Maxwell and Benneworth, 2018; Repko and Szostak, 2017) that integrates the insights of these disciplines. Hence, by drawing on this "gatekeeper" concept, a solution is proposed that can resolve the disciplinary conflicts found within agricultural economics departments. This commentary argues that gatekeepers who institute loosely coupled exchanges among an agricultural economics' core (economics) and peripheral discipline (agribusiness) can advance the 'normal science' of these disciplines, while supporting an integration of insights that appeals to these disciplines' common interests. While this gatekeeping function is proposed as one possible solution for agricultural economics departments, this gatekeeping role can also be extended to other departments facing similar disciplinary conflicts. As result, this commentary contributes to ID research where the concept of a gatekeeper offers a unique means to integrate the disciplinary insights necessary for the advancement of ID approaches in higher education institutions.

\section{Conceptual developments}

Interdisciplinarity. Since integration is a central feature of interdisciplinarity (Menken and Keestra, 2016; Repko and Szostak, 2017), the goal of interdisciplinarity is to integrate the insights of different disciplines into solving complex problems that cannot be adequately addressed by any given discipline (Clark and Wallace, 2015; Menken and Keestra, 2016; Repko and Szostak, 2017). Interdisciplinarity is defined as

...a set of practices; asking research questions that do not necessarily constrain theories, methods, or phenomena; drawing upon diverse theories and methods... and integrating the insights of those disciplinary scholars in order to achieve a holistic understanding. (Repko and Szostak, 2017, p. 9)

Given its emphasis on the integration of insights, researchers have further delineated interdisciplinarity in terms of its instrumental and critical dimensions (Repko and Szostak, 2017). Instrumental interdisciplinarity emphasizes the borrowing and combining of the insights of different disciplines into solving practical problems of society (e.g., grand challenges) (Batie, 2008; Clark and Wallace, 2015; Repko and Szostak, 2017). The implicit assumption of instrumental interdisciplinarity is that the borrowing and combining of these disciplinary insights is predicated on advancing the disciplinary expertise of the contributing disciplines. In other words, disciplines are foundational to instrumental interdisciplinarity (Repko and Szostak, 2017). Yet, as the goal of interdisciplinarity is to develop a holistic understanding of complex problems (Menken and Keestra, 2016; Repko and Szostak, 2017), critical interdisciplinarity seeks more than a borrowing and combining of different disciplinary insights. Critical interdisciplinarity seeks a holistic understanding by "....interrogat[ing] the dominant structure of knowledge and education with the aim of transforming them, while raising epistemological and political question of value and purpose" (Repko and Szostak, 2017, p.9). Unlike instrumental interdisciplinarity, critical interdisciplinarity seeks to dismantle the boundaries between disciplines by transforming the combined disciplines in ways that offer a more comprehensive and holistic understanding and solution to complex problems (Repko and Szostak, 2017).

Challenges with ID. While some contend that interdisciplinarity -especially instrumental interdisciplinarity-will become the dominant educational paradigm, departments are traditionally organized along core disciplinary lines or silos (Brewer, 1999). A core discipline is organized around a self-referential (Maxwell and Benneworth, 2018) system whose purpose is to reinforce a discipline's "normal science" (see also Becher and Trowler, 2001; Kuhn, 1962). This 'normal science' involves promoting a shared understanding of the core or key assumptions, theories and methods of a discipline (Kuhn, 1962). Yet, by developing a shared commitment to the assumptions, theories and methods of a core discipline, the advancement of "normal science" resists or rejects less established or peripheral disciplines that do not share the same core (Becher and Trowler, 2001; Kuhn, 1962). Agricultural economics departments have historically been organized around a core economic discipline. The core activities of agricultural economics departments involve a "normal science" that refines established economic theories and to offer better estimation methods and techniques in supporting the assumptions of the economic discipline (e.g., Debertin et al., 1995). Yet, over the last 30 years, the discipline of agribusiness has been a significant contributor to the growth of the undergraduate and graduate programs of many agricultural economics departments. The growth of the agribusiness discipline has offset declines in the enrollment of traditional agricultural economics programs (Detre et al., 2011). The number of faculty involved in the teaching as well as research of agribusiness in agricultural economics departments have subsequently increased where the agribusiness discipline has become an important component of many agricultural economics departments (Detre et al., 2011). Yet, while this growth has broadened the core economic discipline of agricultural economic departments, the agribusiness discipline is often viewed as a peripheral discipline. This is because agribusiness does not share the same rational assumptions, 'formal rational logic,' quantitative methods and epistemologies (mathematical-deductive rationalizations) of economics ( $\mathrm{Ng}$ and Siebert, 2009). The integration of the peripheral agribusiness discipline into agricultural economics departments has thus been a source of conflict because agribusiness undermines the shared commitment necessary to advancing the 'normal science' of a department's economic core (see also Sonka and Hudson, 1989).

Ambidexterity research. To reconcile this conflict we appeal to developments in ambidexterity research. (Boumgarden et al., 2012; O'Reilly and Tushman, 2013; Raisch and Birkinshaw, 2008; Tushman and O'Reilly, 1996). Ambidexterity refers to an organization's ability to simultaneously attend to internally contradictory knowledge structures (Boumgarden et al., 2012; O'Reilly and Tushman, 2013; Raisch and Birkinshaw, 2008) or "dominant 
logics" (Prahalad and Bettis, 1986). A dominant logic is analogous to Kuhn's (1962) concept of a discipline that consists of an organization's key assumptions, commitments, experiences, values and beliefs about how an organization should compete in its core lines of business (Prahalad and Bettis, 1986). Like a discipline, a dominant logic seeks a consensus by focusing an organization's attention to knowledge and actions that affirms an organization's dominant logic. This affirmation simplifies complex decision settings by focusing an organization's attention to actions that reinforce the success and growth of an organization's core (Prahalad and Bettis, 1986). Yet, as complex decisions often require the use of multiple disciplines (Maxwell and Benneworth, 2018; Repko and Szostak, 2017) or new logics, an organization faces pressures to adopt new logics (Prahalad and Bettis, 1986). These new logics tend to be peripheral to the dominant logic of an organization's core because they offer new ways of doing business that challenge a dominant logic's key assumptions and beliefs (Prahalad and Bettis, 1986).

Ambidexterity researchers also argues that "loosely coupled exchanges" can reconcile internal conflict (Benner and Tushman, 2003; Boumgarden et al., 2012; Danneels, 2003; Raisch and Birkinshaw, 2008). Loosely coupled connections are defined by a semi-autonomous relationship where an organization's peripheral logic is linked but "not fully determined" (Danneels, 2003, p. 560) by the dominant logic of an organization's core (Carter, 2015). This loose coupling resolves organizational conflict by separating the dominant logic of an organization's core from the logics of its peripheral units (Boumgarden et al., 2012; Carter, 2015). With this separation, an organization's peripheral logic can adapt to the complexities of its market environment and not be dictated by the pressures to conform to the dominant logic of an organization's core (Boumgarden et al., 2012; Carter, 2015). Ambidexterity researchers, however, also argue that the logics of peripheral units are not entirely separated from the dominant logic of an organization's core. This is because loose coupling also involves an important "boundary spanning" (Benner and Tushman, 2003; Boumgarden et al., 2012) function that integrates the inconsistencies between an organization's core and peripheral logics.

To elaborate on this boundary spanning function, business studies have shown that "gatekeepers" (Tushman and Katz, 1980; Tushman and Nadler, 1986) play a critical role in instituting an organization's loosely coupled exchanges. However before examining this role, it is important to provide some clarification to the definition of a gatekeeper. The Merriam-Webster definition of a gatekeeper is defined by a "person who controls access", such as an attendant at a gate. Business studies have instead defined the 'gatekeeper' as an individual who is strongly connected across two or more different knowledge domains or logics and has the ability to promote communication between these domains (e.g., Tushman and Scanlan, 1981; Whelan et al., 2010). This "gatekeeper" is normally a senior project leader who is not only strongly connected to the members of their business unit but is also linked to members in other business units (Tushman and Katz, 1980). This business characterization of the "gatekeeper" concept was developed in response to the increasing specialization of organizational units (Tushman and Scanlan, 1981; Whelan et al., 2010). The specialization of an organization's unit's skills (i.e., marketing, production, finance, human resources departments) have led to the creation of localized norms, values, vocabularies and methods that are tailored to the specific requirements of that unit (Tushman and Scanlan, 1981). This specialization created domain specific vocabularies and language where "communication boundaries" (Tushman and Scanlan, 1981, p. 290) precluded the transmission of information across an organization's different units. The business concept of a "gatekeeper" was developed in response to overcoming this "communication boundary". Hence, an important distinction of the business definition of a "gatekeeper" is it seeks to promote rather than restrict access to information (Tushman and Katz, 1980, p. 1072; Tushman and Scanlan, 1981). This distinction is reflected by a "gatekeeper's" boundary spanning function. This boundary spanning function involves bridging an organization's core and peripheral logics by integrating elements that are common to these different knowledge structures (e.g., Benner and Tushman, 2003; Boumgarden et al., 2012; Raisch et al., 2009). Business studies have found a large body of evidence that not only supports the existence of this characterization of "gatekeepers", but also provide evidence in support of their boundary spanning function (Tushman and Katz, 1980; see also Whelan et al., 2010 for a review of "gatekeeper" research). Since the task of this commentary is to bridge the different disciplines of agricultural economics departments, we adopt a business study definition of 'gatekeepers' rather than a Merriam-Webster definition.

Granted that public institutions vary in a number of substantive ways from for-profit organizations, "gatekeepers" can play an important loose coupling role for agricultural economics departments. We define "gatekeepers" as senior or tenured faculty members whose functions are to advocate the merits and relevance of a department's peripheral disciplines to its department's disciplinary core. These "gatekeepers" operate in an advisory capacity where they are separated from the decision processes of the department head and administrative teams. The department head and administrative teams tend to place a greater focus on research, teaching and funding activities that advance the "normal science" of the department's economic core. By separating the "gatekeeper" from these decision processes, the "gatekeeper" has the autonomy to advocate the merits of a peripheral discipline, such as agribusiness, independently of the dominant logic of a department's economic core.

While a "gatekeeper" is structurally separated from the department's core decision making process, the "gatekeeper" nevertheless plays an important advocacy role that seeks to reconcile the conflicts between a department's core and peripheral disciplines. In order to understand this advocacy, the loosely coupled relationships between an agricultural economics department's peripheral and core disciplines need to be first explained. A peripheral discipline, such as agribusiness, must be coupled to the economic core of most agricultural economic departments. This is because agribusiness programs are administratively housed within agricultural economics departments and not in business departments (see exceptions Morrison School of Agribusiness is housed within the W.P. Carey School of Business at Arizona State University) (Harling, 1995; Ng and Siebert, 2009). Although "linked" to the departments of agricultural economics, agribusiness faculty members have a degree of autonomy in their teaching and research programs. Agribusiness faculty engage in research and teaching activities where the assumptions surrounding how agribusiness firms behave, the fundamental questions of research interest, the units of analysis, and the methods of examinations are not dictated by faculty members in the department's economic core. This autonomy enables agricultural economics departments to engage in teaching and research activities that are not addressed by the department's economic core ( $\mathrm{Ng}$ and Siebert, 2009). This greater flexibility, however, comes at a cost of the agribusiness faculty member being ostracized by the department's economic core. This is because the agribusiness discipline operates on a new type of logic where its assumptions, theories and methods tend to be resisted by the dominant logic of a department's economic core. Studies have shown that economic disciplines tend to exhibit a selfreferential bias that is skeptical of contributions made by other social science disciplines (Pieters and Baumgartner, 2002). This 
appears to be supported in agricultural economics settings where disciplinary activities that promote the use of economics are given greater priority over other subject areas (e.g., Hilmer and Hilmer, 2005; Mooney et al., 2013), such as agribusiness (Detre et al., 2011). As a result, the task of the "gatekeeper" is not only to advocate the merits of a department's peripheral discipline to its economic core, but also to resolve and integrate their inconsistencies.

To resolve this internal inconsistency, a "gatekeeper's" advocacy involves instituting loosely coupled exchanges that seek a "common ground" (Maxwell and Benneworth, 2018; Repko and Szostak, 2017) between a department's core and its peripheral discipline. According to ID research, this "common ground" involves integrating conflicting disciplines by either seeking an objective that is common to the affected disciplines (Maxwell and Benneworth, 2018) and/or "modifying one or more concepts or theories and their underlying assumptions" (Repko and Szostak, 2017, p. 269). For instance, a key assumption underlying the economic discipline of agricultural economics is that decision makers are rational and calculative agents. The agribusiness discipline, however, has challenged this fundamental assumption where psychological biases and decision heuristics are increasingly recognized as key influences on an individual's decision making process (Hobbs and Mooney, 2016; Ng et al., 2009). Despite these differences, both agribusiness and agricultural economics share a common goal in explaining an individual or firm's decision making process (Cook and Chaddad, 2000; King et al., 2010). The task facing the "gatekeeper" is to advocate a shared commitment by agribusiness and agricultural economics faculty to develop teaching and research programs that achieves this common goal. "Gatekeepers" make it possible to integrate the behavioral explanations of agribusiness firms into the individual's decision making process by examining departures in the assumptions of the rational economic paradigm. This common ground is most likely to occur with "gatekeepers" who have a significant influence, stature, or power within the department (see Brandstädter and Sonntag, $2016^{1}$, for other factors). Through this common ground, these "gatekeepers" can reconcile and integrate insights from an agricultural economics department's economic and agribusiness disciplines where this integration offers a more integrative or holistic understanding of an individual's decision making process.

A "gatekeeper's" advocacy also involves instituting a loose coupling that addresses the "epistemological dominance" (Maxwell and Benneworth, 2018, p. 2) in a department's economic core. Epistemological dominance occurs when a dominant discipline

demands that other disciplines accept its epistemic assumptions...[where]...this epistemological dominance can then frame, shape, or otherwise prioritize those of the dominant field(s), while marginalizing the value judgment of the less ideal type fields. (Maxwell and Benneworth, 2018; p. 2)

The problem of epistemological dominance is that a peripheral discipline such as agribusiness is forced to conform to the 'normal science' of its department's economic core. This epistemological dominance was noted in Harling (1995) where he describes

a basic philosophical challenge faced by agribusiness researchers: [is that] agribusiness researchers...want to be true to their own predilections towards management yet have to satisfy the majority [agricultural economics] that thinks in terms of economics. (p. 509)

The task of the "gatekeeper" is to forge loosely coupled exchanges that evaluate peripheral disciplines-such as agribusiness-based on their own terms and not those of its core. This loose coupling involves championing to the department head and administrative team, a distinct system of evaluation and rewards that support the growth of the peripheral discipline. This involves a loosely coupled relationship where a peripheral discipline is evaluated and rewarded for advancing the 'normal science' of those disciples (i.e., business) that fall outside of the agricultural economics department's economic core. This peripheral discipline is also evaluated and rewarded on the basis that they advance a "common ground" to the department's economic core. For instance, the academic contributions of the agribusiness discipline are evaluated in accordance to discipline specific journals (i.e., business and closely related social science journals). Also the agribusiness discipline is evaluated in accordance to efforts to advance an understanding of the individual decision making process that transcends the limits of its own discipline and that of its department's economic core (see e.g., Cook and Chaddad, 2000; King et al., 2010).

To summarize our arguments in broader terms, this commentary argues that because "gatekeepers" are central to instituting an agricultural economics department's loosely coupled exchanges, such loose coupling offers a department a unique advantage in managing its internal conflicts. By drawing on a key tenet of ambidexterity research, researchers have found that loosely coupled exchanges enable an organization to leverage its core dominant logic, while at the same time to engage in new or peripheral logics that sustain an organization's adaptiveness to its market environment (Boumgarden et al., 2012; Danneels, 2003). Empirical and case study research has found robust support for this ambidextrous behavior where this ambidexterity has been strongly related to an organization's sales growth, subjective ratings on performance, innovations, market valuations, and a variety of other firm performance metrics (see O'Reilly and Tushman, 2013). This commentary argues that "gatekeepers" who institute a loose coupling of an agricultural economics department's core and peripheral disciplines can realize similar benefits of ambidexterity. Specifically, by drawing on the advocacy and boundary spanning roles of the "gatekeeper", a "gatekeeper" who institutes a department's loose-coupled connections can offer a separation that advances the "normal science" of a department's economic core and its peripheral discipline in agribusiness, while at the same time, support a "common ground" that appeals to these disciplines' common interests. As agricultural economics faces increasing pressures to respond to the needs and problems of different stakeholder groups, agricultural economics departments that draw on such loose coupling will be in a better position to integrate the insights of its different disciplines to meet the needs of these different groups. Those that do not will find their department's significance and relevance to stakeholders questioned. This is aptly described by a former agricultural economist and Dean who noted

the days of hard-funded technicians and graduate research assistants are over, and we will have to behave more like Colleges of Sciences. This has long been recognized by the production agriculture disciplines, and Ag Econ units are beginning to come to the same realization...many of the opportunities for extramural grants for [agricultural] economists involve interdisciplinary research. This underscores the increasing importance of interdisciplinary research, not only to address issues, but also for the sheer survival of the Ag Econ profession. (D. Bernardo, Dean of College of Agricultural, Human, and Natural Resource Sciences, Washington State University, e-mail communication, August 3, 2011) (Mooney et al., 2013, p. 189) 


\section{Discussion and conclusions}

Various researchers have recognized the institutional difficulties and challenges in integrating new systems of thought within an established discipline (e.g., Bammer, 2017; Brandstädter and Sonntag, 2016; Clark and Wallace, 2015; Jacob, 2015; Maxwell and Benneworth, 2018; Mooney et al., 2013). To overcome such challenges, various ID scholars contend that communication is central to the integration of insights from different disciplines (e.g., Brandstädter and Sonntag, 2016; Maxwell and Benneworth, 2018; Menken and Keestra, 2016; Repko and Szostak, 2017). Yet, such communications are primarily examined within a research project setting where the issue of how a department reconciles the conflicts in its core and peripheral discipline remains largely under-examined. By drawing on the advocacy and boundary spanning roles of the "gatekeeper," a central argument of this commentary is that "gatekeepers" who institute a department's loosely coupled connections can offer a separation that advances the "normal science" of a department's core and peripheral disciplines, while at the same time, supports a "common ground" that appeals to these disciplines' common interests. By drawing on this central argument, we offer three contributions to ID research.

First, consensus in ID research is that shared communications are key to overcoming disciplinary conflicts (Brandstädter and Sonntag, 2016; Maxwell and Benneworth, 2018; Menken and Keestra, 2016; Repko and Szostak, 2017). This commentary makes the contribution that a "gatekeeper's" loose coupling promotes a common interest that can sustain a genuine engagement of a department's core and peripheral disciplines. A "gatekeeper's" loose coupling can facilitate critical forms of interdisciplinarity where such loose coupling can fundamentally question and transform the dominant logic of department's economic core. By forging such loosely coupled exchanges, "gatekeepers" not only expose a department's dominant logic to the new logics of its peripheral disciplines, but as a result raise epistemological questions about a department's sustained commitment to its core. Hence, a "gatekeeper's" loose coupling can enable the very collaborations/incentives necessary for the advancement of interdisciplinarity in higher educational institutions and can play a transformative role in transcending a department's disciplinary boundaries.

Second, since interdisciplinarity is a response to complex problems, ID researchers have argued that the insights of complexity science can be useful in addressing such problems (Batie, 2008; Menken and Keestra, 2016; Repko and Szostak, 2017). Although the insights of complexity science have not be fully explored in ID research, complexity researchers have appealed to Ashby's (1956) principle of requisite variety in solving complex problems (Boisot and McKelvey, 2011). This principle states that "an adaptive system survives to the extent that the variety it generates matches that of the environment it finds itself in" (Boisot and McKelvey, 2011, p. 281). As colleges and departments of agricultural economics face increasing pressures to meet the demand of different societal stakeholders (i.e., students, farmers, food businesses, ag. policy makers and legislatures, alternative/ bio-energy, and climate change constituents, etc.), the principle of requisite variety suggest that departments with a greater diversity of disciplines are more likely to meet the demands of these varied stakeholders. This commentary offers a unique means of organizing departments in a way that can develop such requisite diversity. Departments that form loosely coupled exchanges amongst their core and peripheral disciplines offer a means to integrate these disciplines. The integration of these disciplines can result in developing a greater variety of disciplinary insights that a department can draw in meeting the demands of its social stakeholders.
Third, according to the Association of American Colleges and Universities (2003), the increasing specialization of disciplines in higher education (Kleinberg, 2008) has been met by an increasing growth of 'interdisciplinary studies' programs. ID studies are viewed as "a major selling point for colleges and university..." where some "even claim that the twenty first century marks the ascension of interdisciplinarity as the dominant educational paradigm" (Kleinberg, 2008). The challenge, however, raised by Kleinberg (2008) is that the majority of these programs are "not substantially different from the academic disciplines, departments, and divisions they were originally designed to challenge." This suggests that in order to sustain the continued growth of ID studies in high educational institutions, ID studies programs face an increasing need to differentiate themselves from those of its disciplinary counterparts. While the role of "gatekeepers" is primarily confined to integrating the disciplinary insights of a departmental unit, the concept of "gatekeepers" can nevertheless offer an important source of differentiation for ID studies programs. ID studies can institute "gatekeepers" whose function is to establish loosely coupled connections to external department units. Such loosely coupled connections not only strengthen the disciplinary foundations of ID studies programs, but offer an important source of differentiation. As a result, the proposed concept of a "gatekeeper" introduces a loosely coupled exchange that can be an important source of differentiation; a differentiation that may be necessary to advancing ID studies programs into the twenty-first century.

Received: 26 July 2018 Accepted: 12 February 2019

Published online: 05 March 2019

\section{Notes}

1 In addition, their study identified five types of competencies-topic, special, leadership, team and work-that significantly influenced ID collaborations.

\section{References}

Ashby WR (1956) An introduction to cyerbnetics. Chapman \& Hall, London Bammer G (2017) Should we discipline interdisciplinarity? Palgrave Commun https://doi.org/10.1057/palcomms.2015.37

Batie S (2008) Wicked problems and applied economics. Am J Agric Econ 90 (5):1176-1191

Becher T, Trowler P (2001) Academic tribes and territories: intellectual enquiry and the culture of disciplines, 2nd edn. The Society for Research into Higher Education \& Open University Press, Buckingham

Benner MJ, Tushman ML (2003) Exploitation, exploration, and process management: the productivity dilemma revisited. Acad Manag Rev 28(2):238-256

Boisot M and McKelvey B (2011) Complexity and organization-environment relations: revisiting Ashby's law of requisite variety. In: Allen P, Maguire S, and McKelvey B (eds) The Sage handbook of complexity and management. pp. 279-295, Sage Publications, Thousand Oaks, CA

Boumgarden P, Nickerson J, Zenger TR (2012) Sailing into the wind: exploring the relationships among ambidexterity, vacillation, and organizational performance. Strateg Manag J 33(6):587-610

Brewer GD (1999) The challenges of interdisciplinarity. Policy Sci 32(4):327-337

Brandstädter S, Sonntag KH (2016) Interdisciplinary collaboration-how to foster the dialogue across disciplinary borders? In: Deml B, Stock P, Bruder R, Schlick C (eds) Advances in ergonomic design of systems, products and processes. Spring, Berlin, p 395-409

Carter WR (2015) Ambidexterity deconstructed: a hierarchy of capabilities perspective. Manag Res Rev 38(8):794-812

Clark SG, Wallace RL (2015) Integration and interdisciplinarity: Concepts, frameworks, and education. Policy Sci 48(2):233-255

Cook ML, Chaddad FR (2000) Agro industrialization of the global agrifood economy: bridging development economics and agribusiness research. Agric Econ 23(3):207-218

Danneels E (2003) Tight-loose coupling with customers: the enactment of customer orientation. Strateg Manag J 24(6):559-576

Debertin DL, Luzar EJ, Chambers OD (1995) A protocol or a set of standards to guide agricultural economics research. J Agric Resour Econ 20(1):82-95 
Detre JD, Gunderson MA, Peake WO, Dooley FJ (2011) Academic perspectives on agribusiness: an international survey. Int Food Agribus Manag Rev 14 (5):141-165

Harling KF (1995) Differing perspectives on agribusiness management. Int J Agribus 11(6):501-511

Hilmer CE, Hilmer MJ (2005) How do journal quality, co-authorship, and author order affect agricultural economists' salaries? Am J Agric Econ 87(2):509-523

Hobbs JE, Mooney S (2016) Applications of behavioral and experimental economics to decision making in the agricultural, food, and resource sectors: an introduction. Canadian. J Agric Econ 64(4):593-597

Jacob W (2015) Interdisciplinary trends in higher education. Palgrave Commun. https://doi.org/10.1057/palcomms.2015.1

King RP, Boehlje M, Cook ML, Sonka ST (2010) Agribusiness economics and management. Am J Agric Econ 92(2):554-570

Kleinberg E (2008) Interdisciplinary studies at a crossroads. Lib Edu. https://www. aacu.org/publications-research/periodicals/interdisciplinary-studiescrossroads

Kuhn TS (1962) The structure of scientific revolutions.. University of Chicago Press, Chicago, IL

Markoczy L, Deeds DL (2009) Theory building at the intersection: recipe for impact or road to nowhere. J Manag Stud 46(6):1076-1088

Maxwell K and Benneworth P (2018) The construction of new scientific norms for solving grand challenges. Palgrave Commun. https://doi.org/10.1057/s41599018-0105-9

Menken S, Keestra M (2016) An introduction to interdisciplinary research: theory and practice. Amsterdam University Press, Amsterdam, (eds)

Mooney S, Young D, Cobourn K, Islam S (2013) Multidisciplinary research: implications for agricultural and applied Economists. J Agric Appl Econ 45 (2):187-202

Ng D, Siebert JW (2009) Towards better defining the field of agribusiness management. Int Food Agribus Manag Rev 12(4):123-142

$\mathrm{Ng}$ D, Westgren R, Sonka S (2009) Competitive blind spots in an institutional field. Strateg Manag J 30(4):349-369

N.I.F.A (2018) Agricultural research, extension, and education reform act of 1998. National Institute of Food and Agriculture website. https://nifa.usda.gov/ resource/agricultural-research-extension-and-education-reform-act-1998. Accessed 26 Oct 2018

O’Reilly CA, Tushman ML (2013) Organizational, ambidexterity: past, present and future. Acad Manag Perspect 27(4):324-338

Pedersen DB (2016) Integrating social sciences and humanities in interdisciplinary research. Palgrave Commun. https://doi.org/10.1057/palcomms.2016.36

Pieters R, Baumgartner H (2002) Who talks to whom? Intra and interdisciplinary communications of economics journals. J Econ Lit 40(2):483-509

Prahalad CK, Bettis RA (1986) The dominant logic: a new linkage between diversity and performance. Strateg Manag J 7(6):485-501

Raisch S, Birkinshaw J (2008) Organizational ambidexterity: Antecedents, outcomes and moderators. J Manag 34(3):375-409
Raisch S, Birkenshaw JPG, Tushman ML (2009) Organizational ambidexterity: balancing exploitation and exploration for sustained performance. Organ Sci 20(4):685-695

Repko AF, Szostak R (2017) Interdisciplinary research: process and theory, 3rd edn. Sage, Los Angeles

Sonka S, Hudson MA (1989) Why agribusiness anyways. Int J Agribus 5 (4):305-314

Tushman ML, Katz R (1980) External communications and project performance: an investigation into the role of gatekeepers. Manag Sci 26(11):1071-1085

Tushman ML and Murmann JP (1998) Dominant designs, technological cycles and organizational outcomes. In: Staw B and Cummings L (eds.) Research in Organizational Behavior, Vol. 20. JAI Press, Greenwood, Conn.

Tushman ML, Nadler D (1986) Organizing for innovation. Calif Manag Rev 28 (3):74-92

Tushman ML, O’Reilly CA (1996) Ambidextrous organizations: managing evolutionary and revolutionary change. Calif Manag Rev 38(4):8-30

Tushman ML, Scanlan TJ (1981) Boundary spanning individuals: their role in information transfer and their antecedents. Acad Manag J 24(2):289-305

Whelan E, Teigland R, Donnellan B, Golden W (2010) How Internet technologies impact information flows in $\mathrm{R} \& \mathrm{D}$ : reconsidering the technological gatekeeper. R\&D Manag 40:400-413

\section{Additional information}

Competing interests: The authors declare no competing interests.

Reprints and permission information is available online at http://www.nature.com/ reprints

Publisher's note: Springer Nature remains neutral with regard to jurisdictional claims in published maps and institutional affiliations.

(c) (i) Open Access This article is licensed under a Creative Commons Attribution 4.0 International License, which permits use, sharing, adaptation, distribution and reproduction in any medium or format, as long as you give appropriate credit to the original author(s) and the source, provide a link to the Creative Commons license, and indicate if changes were made. The images or other third party material in this article are included in the article's Creative Commons license, unless indicated otherwise in a credit line to the material. If material is not included in the article's Creative Commons license and your intended use is not permitted by statutory regulation or exceeds the permitted use, you will need to obtain permission directly from the copyright holder. To view a copy of this license, visit http://creativecommons.org/ licenses/by/4.0/.

(C) The Author(s) 2019 